NASA Technical Memorandum 105367

AIAA-92-2040

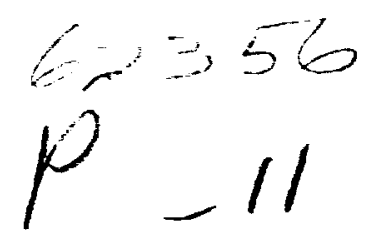

\title{
The Link Evaluation Terminal for the Advanced Communications Technology Satellite Experiments Program
}

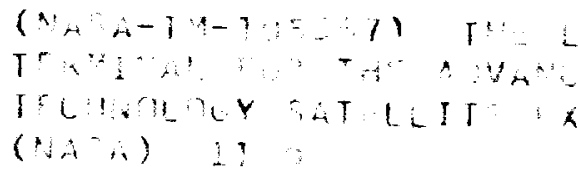

Brian D. May

Lewis Research Center

Cleveland, Ohio

Prepared for the

14th International Communications Satellite Systems Conference sponsored by the American Institute of Aeronautics and Astronautics Washington, D.C., March 22-26, 1992 
The communications band uplink to the satellite is from 29 to $30 \mathrm{GHz}$. While LET has the capability to uplink over the entire band, the modulated test signal ranges from 29.5 to $29.8 \mathrm{GHz}$. The satellite transponder returns communications signals to earth from 19.2 to $20.2 \mathrm{GHz}$. Again, LET can receive over the entire band, but the modulated test signal is translated to 19.8 to $20.1 \mathrm{GHz}$.

During experiments with LET, the payload will be configured in the MSM mode of operation. Uplink communications signals are downconverted on the satellite from the 29 to $30 \mathrm{GHz}$ band to the 3 to $4 \mathrm{GHz}$ band. Any satellite receiver is electronically connected to any satellite transmitter by means of a 3 by 3 switch matrix thereby interconnecting all spot beams. This matrix is an array of dual gate gallium arsenide field effect transistor microwave switches. A ground based computer controls the crosspoints in the MSM which routes the communications signal. The satellite transponder upconverts the 3 to $4 \mathrm{GHz}$ signal to $20 \mathrm{GHz}$ after the MSM for the TWT transmitter.

\section{Capabilities of LET}

The initial phase of the ACTS experiments program will be dedicated to verification of new technology developed during the program. LET will be the only means by
$30 \mathrm{GHz}$ is severe. The LET transmitter has the capability to deliver up to $40 \mathrm{~W}$ of $\mathrm{RF}$ power to the antenna, the level of which is computer controlled by adjusting the transmitter drive level. Experimental algorithms are installed on the control computer to maintain LET communications with the satellite. A beacon signal level from the satellite is monitored so that when the received signal is reduced by atmospheric effects to a predetermined threshold, the transmitter power is increased by adjusting the drive level. Calculations of propagation losses to the satellite at $30 \mathrm{GHz}$ indicate that less than $10 \mathrm{~W}$ of transmit power at the antenna is required to achieve communications with the satellite on a clear day leaving the excesses power available to compensate for rain fade conditions. A p-in diode attenuator under computer control sets the drive level to the TWTA. Experimental algorithms monitoring the measured rain fade attenuation will adjust the $p-i-n$ diode attenuation to compensate for the additional propagation losses. Independent experimenters can load their own rain fade compensation algorithms that sense and act on rain fade events.

Calculations show that LET can continue reliable data reception even when rain adds $12 \mathrm{~dB}$ of attenuation during severe downpours. The maximum $40 \mathrm{~W}$ transmitter output power enables LET to maintain a 
LET has an RF internal loopback path that will be used to monitor the health of LET components. Output from the transmitter is attenuated and downconverted for input to the receiver. Experiments using LET can be simulated on the ground before ACTS satellite resources are committed.

\section{Performance Testing}

Testing of LET has taken place at three different levels to ensure that LET performance characteristics meet design goals. Individual parts were tested upon delivery to NASA Lewis, for example RF components are tested on an Analog Network Analyzer to verify $S$ parameter performance. Parts were assembled into major subsystems that provide basic functions of LET. These major subsystems were examined on an Analog Network Analyzer in addition to special testing such as BER performance. ${ }^{2}$ The major subsystems were finally brought together during the recent integration phase of the LET program. Performance testing of LET at the system level utilized the RF loopback path internal to LET.

Uplink transmit power is provided by a Hughes Traveling Wave Tube Amplifier. Dynamic characteristics of the TWTA alone in Fig. 2(a) show a saturated output power of over $49 \mathrm{dBm}$ ( $85 \mathrm{~W}$ ) which exceeded our $65 \mathrm{~W}$ specification. This value corresponds to a input power level of $-6 \mathrm{dBm}(0.5 \mathrm{~mW})$. Gain at saturated operation is then $55 \mathrm{~dB}$ and increases to $60 \mathrm{~dB}$ when the input power is reduced into the linear region (see Fig. 2(b)). After waveguide circuit losses, $40 \mathrm{~W}$ is available to the antenna. Combined with the 4.72-m diameter antenna gain of $60.4 \mathrm{~dB}$, LET uplink EIRP can be in excess of $75 \mathrm{dBW}$.

The TWTA and p-i-n diode attenuator are integrated with a $30 \mathrm{GHz}$ solid state amplifier and filtering to form the LET transmitter. A two stage upconverter prior to the transmitter completes the transmit side RF path from a 3 to $4 \mathrm{GHz}$ input to the 29 to
$30 \mathrm{GHz}$ output. Swept response of the transmit side is shown in Fig. 3. For this measurement, RF attenuators were set such that a $3.373 \mathrm{GHz}$ signal delivering $-15 \mathrm{dBm}$ to the upconverter would drive the TWTA at $3 \mathrm{~dB}$ below saturation. The transmitter shows peak power performance in the center of the operating band where the LET test signal will be.

The LET test signal is pseudo random digital data modulated as Serial Minimum Shift Keying (SMSK) to generate the LET test signal. SMSK was chosen due to its spectral efficiency and constant amplitude envelope. Motorola built 110.592/221.184 Mbps dual rate SMSK modems for NASA Lewis under a technology development contract. One modem set from this contract is being used by LET.

Performance of the SMSK modems connected back-to-back is shown in Figs. 4 and 5. Figure 4 displays modem performance in a $110.592 \mathrm{Mbps}$ mode of operation with both continuous and burst data throughput. A continuous mode of operation for the LET modems consists of ten 64 bit words of overhead and sufficient random data to fill the entire $250 \mu$ sec burst frame. The $110.592 \mathrm{Mbps}$ burst mode shows measurement results using a $100 \mathrm{Mbps}$ data throughput, but can operate at a discrete throughput ranging from $1.25 \mathrm{Mbps}$ to $55.592 \mathrm{Mbps}$. This mode of operation has 1.0 to $1.5 \mathrm{~dB}$ of degradation from theoretical performance of SMSK. The $110.592 \mathrm{Mbps}$ burst mode is particularly sensitive to increasing noise.

Figure 5 displays modem performance in a 221.184 Mbps mode of operation with both continuous and burst data throughput. Performance of the modems operating in a 221.184 Mbps mode has more degradation than that found in the $110.592 \mathrm{Mbps}$ mode. Again the modems are connected back-toback. The 221.184 Mbps burst rate shows measurement results using a throughput of $200 \mathrm{Mbps}$, but can operate at a discrete throughput ranging from $1.25 \mathrm{Mbps}$ to $110.592 \mathrm{Mbps}$. The modems display up to 
$2 \mathrm{~dB}$ of degradation from theoretical performance of SMSK. SMSK implementation loss of $2.0 \mathrm{~dB}$ beyond theoretical is quite good.

Harris Corporation, under a NASA Lewis development contract, has built a $20 \mathrm{GHz}$ receiver featuring a four stage high electron mobility transistor (HEMT) low noise amplifier at the receiver front end. A monolithic microwave integrated circuit (MMIC) mixer and MMIC amplifiers are packaged with the HEMT amplifier using microwave integrated circuit techniques to downconvert and amplify the $20 \mathrm{GHz}$ received signal to a signal in the 3 to $4 \mathrm{GHz}$ band. Noise figure of the assembled receiver is measured to be $3.5 \mathrm{~dB}^{3}$ Control switches and an intermediate frequency (IF) amplifier are integrated with the Harris receiver to form the receive side $\mathrm{RF}$ path.

Measured noise figure for this path, including all components between the antenna interface to the independent experimenter port, is $5.0 \mathrm{~dB}$. Calculated $\mathrm{G} / \mathrm{T}$ is $26 \mathrm{~dB} / \mathrm{K}$. Swept response of the receive side, from the antenna interface to the experimenter IF port is shown in Fig. 6. For this measurement, a 19.914 GHz RF signal delivered the specified $-65.5 \mathrm{dBm}$ to the antenna receive port. The nearly linear gain slope is repeatable and driven by the Harris receiver.

BER measurements, duplicating procedures performed with the modems connected back-to-back, were made on the integrated LET system. The internal loopback path was used to attenuate and downconvert the transmitter signal for insertion into the receiver. Results for 110.592 Mbps burst mode with $100 \mathrm{Mbps}$ throughput is shown in Fig. 7. In this case the loopback path bypassed the TWTA. BER measurements show close performance to that of the modems back-to-back. Inserting the TWTA into the loopback path adds 0.5 to $1.0 \mathrm{~dB}$ of degradation as shown in Fig. 8. Results for 221.184 Mbps burst mode with $200 \mathrm{Mbps}$ throughput is shown in Fig. 9. This loopback path also includes the TWTA. It is concluded from this measurement that the LET internal loopback path has minimal detrimental impact on the test signal. Implementation loss from theoretical SMSK performance is a maximum of $3.0 \mathrm{~dB}$ when operating in the 221.184 Mbps mode. Therefore the loopback path can adequately serve two very important functions; to verify the health of LET RF equipment and allow experiment rehearsal before communicating with the satellite.

\section{Technology Verification Experiments}

During the first several months of ACTS being on orbit, spacecraft operations will be reserved for verification testing. The spacecraft bus command and control system will first check out basic housekeeping functions for proper operation. NASA will then exercise the MSM and baseband processor capabilities during technology verification experiments. This phase of the ACTS experiments program will verify that the new, high risk technology developed for the ACTS program does indeed work in the space environment. These experiments will be repeated periodically to document how well the new technology holds up.

LET support of the technology verifications experiments is naturally focused on the MSM mode of operation. Transponder frequency response will be measured for a variety of paths through the payload. Ideally every path would be examined, but time considerations may limit the number of tests performed. The measured frequency response as observed on the ground will be used to determine $1 \mathrm{~dB}$ bandwidth, $3 \mathrm{~dB}$ bandwidth and gain ripple of the transponder paths. Archived beacon signal power levels will be used to separate propagation effects from transponder effects. A minimum $1 \mathrm{~dB}$ bandwidth of $900 \mathrm{MHz}$ is the specified for the payload, but $20 \mathrm{GHz}$ beacons at the top end of the downlink frequency band (see Fig. 10) reduce LET's practical system bandwidth to an estimated $800 \mathrm{MHz}$.

A subset of transponder paths from above will be tested for BER performance using inherent LET capability. Burst rates of 
both 220 and $110 \mathrm{Mbps}$ will be routed through the transponder. The return signal from the payload will be examined for bit errors to determine the accumulated effects of the propagation path and the transponder on the quality of the communications path. Some degradation is naturally expected, but the amount of degradation is not know with any certainty at this time. Transponder paths exhibiting unwanted large amplitude gain ripple would affect $B E R$ performance severely. ${ }^{4}$

The dynamics of the MSM will be examined by observing a simple carrier tone routed through various crosspoints. Switch states of the MSM will be programmed to enable or disable the downlink signal to LET. Since LET is a unique ground terminal, the verification experiments are limited in this area. LET will record transition from one switch state to the next as downlink signal is observed from the ground. Switch state transition timing is expected to be 100 nsec. Transition timing and distortion due to any overshoot that may be present are parameters that are of interest.

Transponder resources can be shared such that two independent communications modes are established through the satellite. The MSM mode which LET uses will be tested with swept frequency response and BER meaurements while the baseband processor mode is also running. There is not expected to be any degradation of either communications mode, but the measurement data will be examined for crosstalk effects on swept response and BER performance.

\section{Independent Experimenter Interface}

Provisions are incorporated in LET that allow independent experimenters to use the transmitter and receive chain of LET. The experimenter would interface to both the upconverter and downconverter via subminiature A (SMA) female connectors. The RF components of LET were designed to accommodate the SMSK modems, therefore the upconverter input power is nominally $-15 \mathrm{dBm}$ and the receiver chain will nominally deliver $-33 \mathrm{dBm}$. Both upconverter/ transmitter and receive chain performance are optimized for a signal center frequency at $3.373 \mathrm{GHz}$. Alternative frequency plans are possible within the constraints of the LET operating bandwidth (see Fig. 10).

Prior to any experiment, configuration of the LET RF equipment will take place using computer control. Independent experimenters can design the configuration to be static or dynamic during the experiment. An example of dynamic configuration is executing rain fade compensation software while an independent experiment is running. Computer archiving can record instrument measurements, such as power level, for future examination.

The Jet Propulsion Laboratory (JPL) is proposing a mobile terminal experiment using ACTS in the MSM mode. A small ground terminal mounted on a vehicle is to roam the Los Angeles area while communicating with LET which simulates a network hub station. JPL will connect to LET communications equipment compatible with the mobile terminal to provide a duplex channel through the satellite. This experiment will explore the potential of Ka-Band in supporting mobile users. A severe propagation environment and compact mobile terminal equipment are the technical challenges facing the mobile experiment.

\section{$\underline{\text { Conclusion }}$}

LET has been designed to be a flexible experiment platform in order to perform a number of functions. Primary activity at the beginning of ACTS on orbit operation is verification of technology developed for the communications payload. These tests are to be repeated periodically to document the robustness of the new technology in the space environment. Throughout the experiment period of ACTS, LET RF subsystems will be used by independent experimenters for testing of 
new applications of communications in the Ka-Band.

Measurements of LET performance in the laboratory environment has been reproduced here. BER measurements indicate that the LET RF subsystems will have minimal impact on the performance of experiments.

\section{$\underline{\text { References }}$}

1. Naderi, F.M., and Campanella, S.J., "NASA's Advanced Communications Technology Satellite (ACTS): An Overview of the Satellite, the Network, and the Underlying Technologies," AIAA Paper 88-0797, Mar. 1988.
Laboratory-Simulated $30 / 20 \mathrm{GHz}$ Communications Satellite Transponder," AIAA Paper 90-0808, Mar. 1990 (also, NASA TM-102424).

3. "NASA-Lewis Research Center $20 \mathrm{GHz}$ Receiver POC fab and Manufacturing Test Review," Harris Corp., Mar. 23, 1988, NASA Contract NAS3-24244.

4. Kerczewski, R.J., and Fujikawa, G., Svoboda, J.S., and Lizanich, P.J., "Effects of Amplitude Distortions and IF Equalization on Satellite Communication System Bit-Error Rate Performance," AIAA Paper 90-0878, Mar. 1990 (also, NASA TM-102415).

2. Kerczewski, R.J., and Fujikawa, G., "Performance Measurements for a

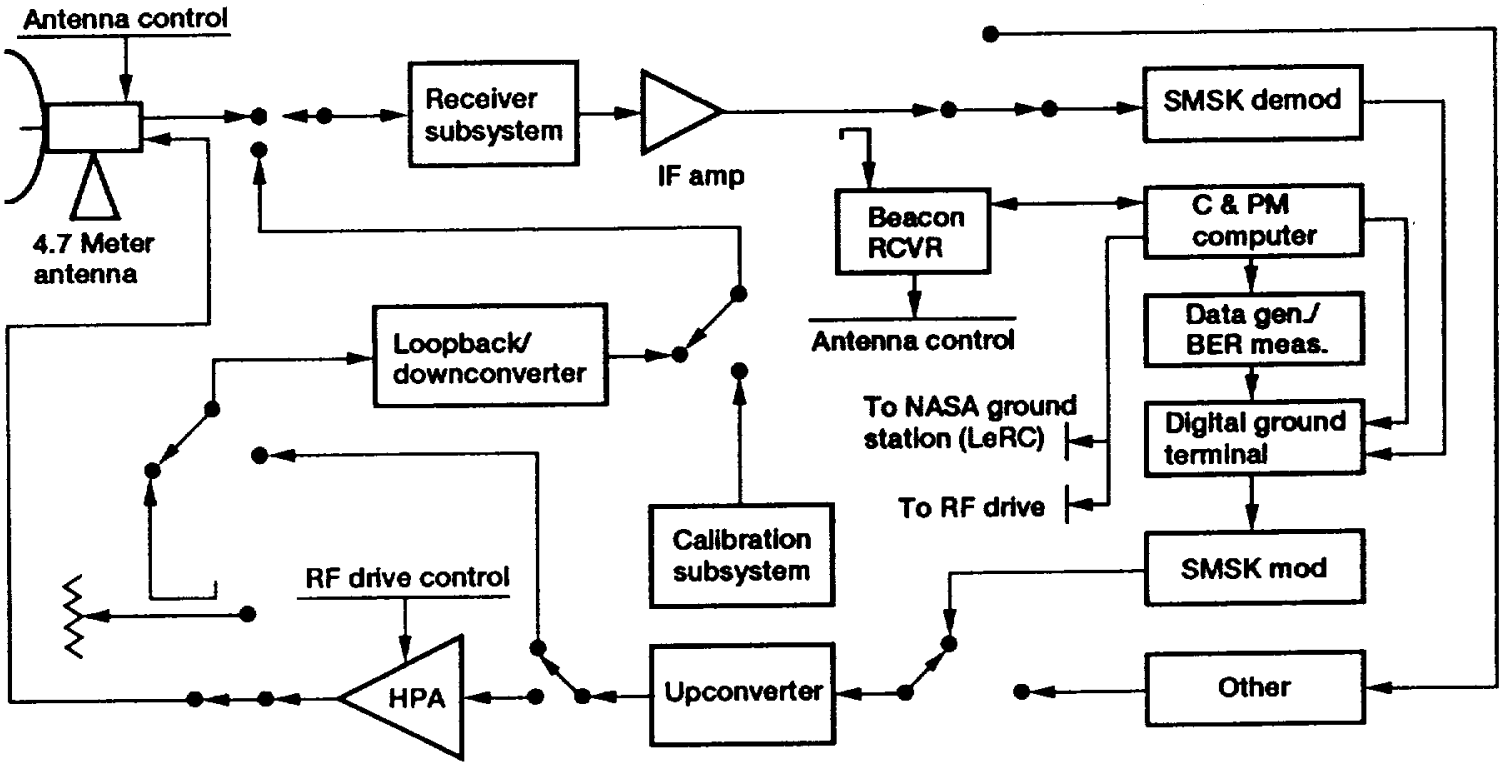

Figure 1.- Link Evaluation Terminal block diagram. 


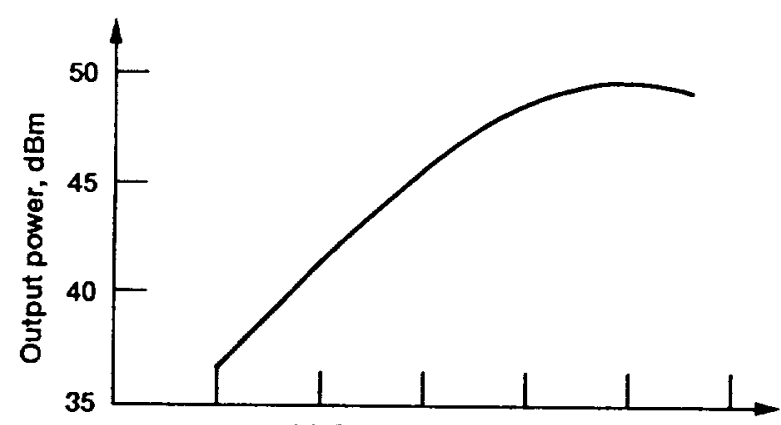

(a) Output power.



(b) Galn.

Figure 2.-TWTA Serial Number 49002 characteristics at $29.6 \mathrm{GHZ}$

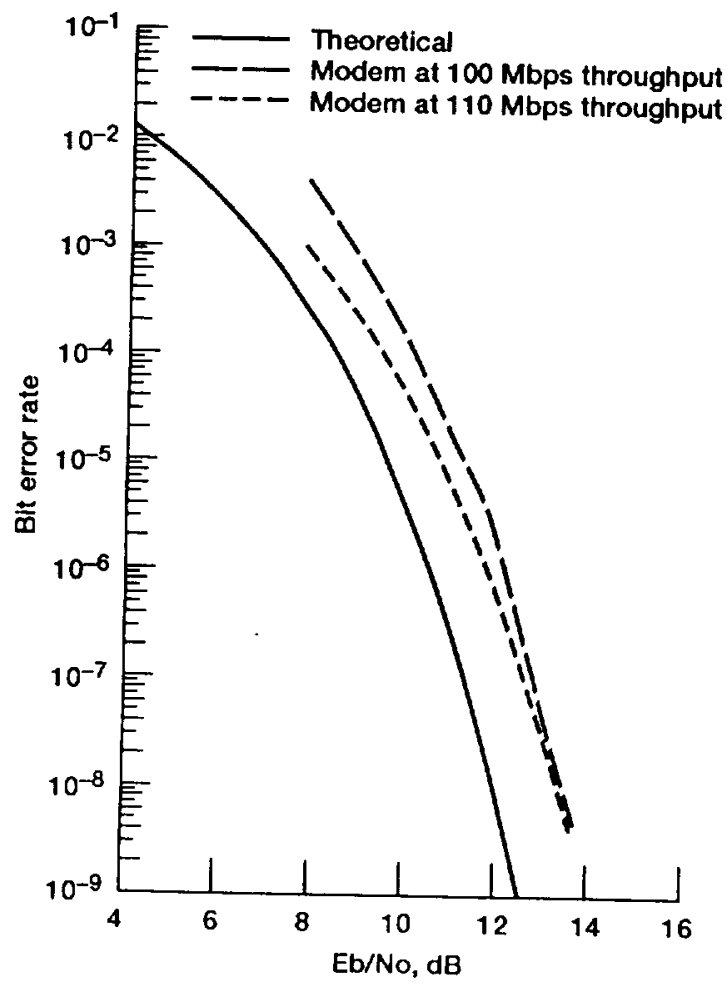

Figure 4.-BER performance of the LET SMSK modems in the 110.592 Mbps mode with continuous and burst throughput. Modems are connected back-to-back.

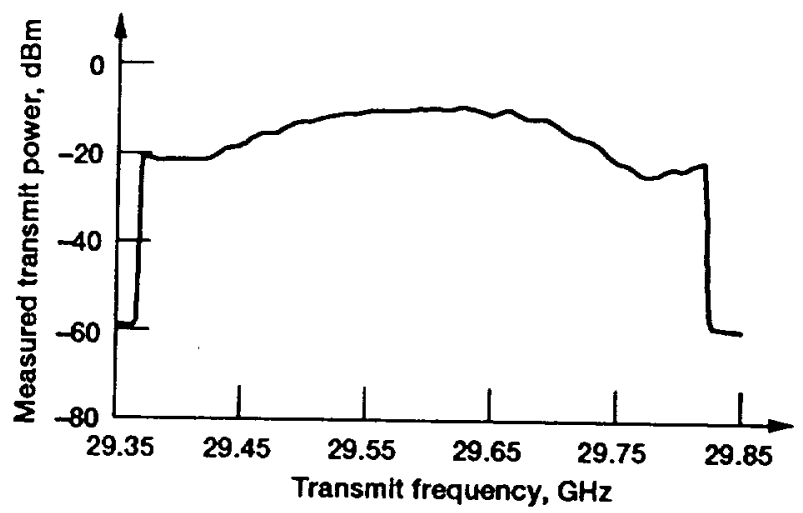

Figure 3.-Swept response of the upconverter/transmitter RF chain from the experimenter Interface to a $40 \mathrm{~dB}$ coupler on the antenna port. Conversion loss $=36.5 \mathrm{~dB}$, resolution bandwidth $=1.0 \mathrm{MHz}$, video bandwidth $=3.0 \mathrm{MHz}$, and sweep time $=25.0 \mathrm{msec}$.

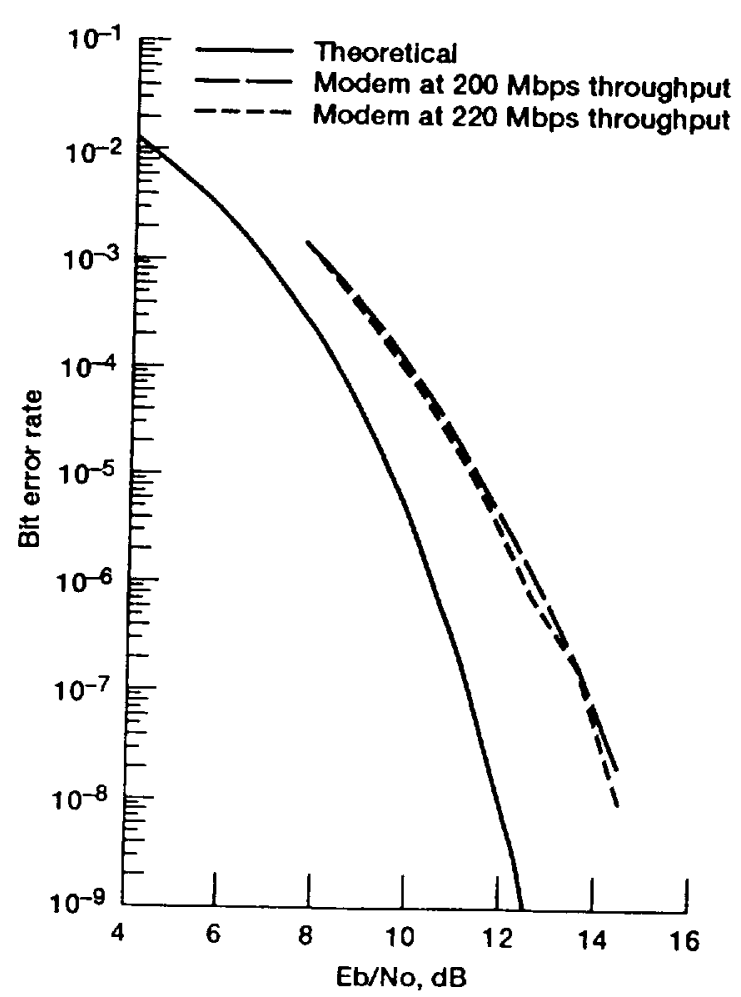

Figure 5.-BER performance of the LET SMSK modems in the 221.184 Mbps mode with continuous and burst throughput. Modems are connected back-to-back. 


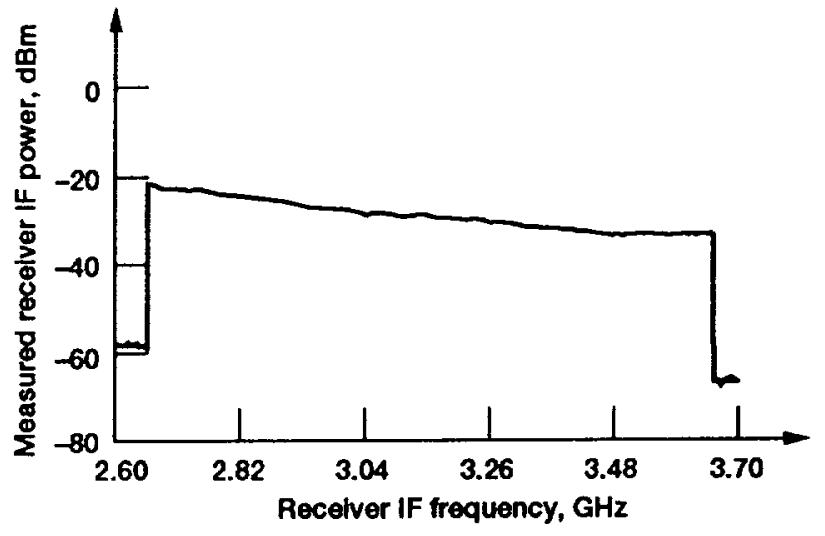

Figure 6. Swept response of the recelve RF chain from the antenna port to the experimenter interface. $10 \mathrm{~dB}$ of spectrum analyzer attenuation, resolution bandwidth $=300 \mathrm{kHz}$, video bandwidth $=300 \mathrm{kHz}$, and sweep time $=50.0 \mathrm{msec}$.

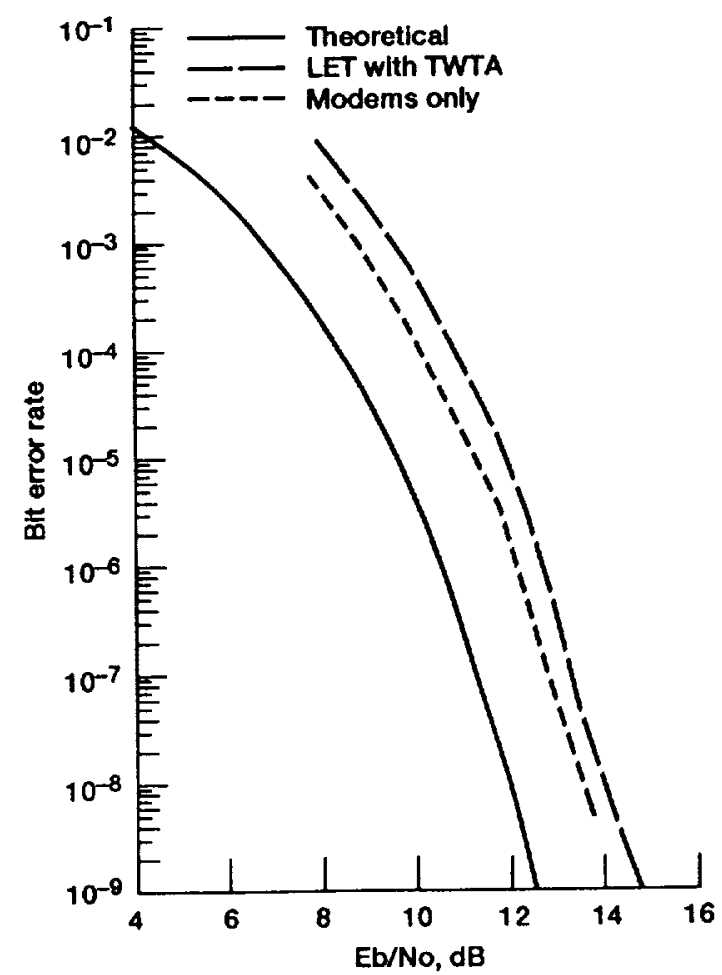

Figure 8.-BER performance of the LET Loopback path including the TWTA 110.592 Mbps burst mode with 100 Mbps throughput. Modem back-to-back case included for reference.

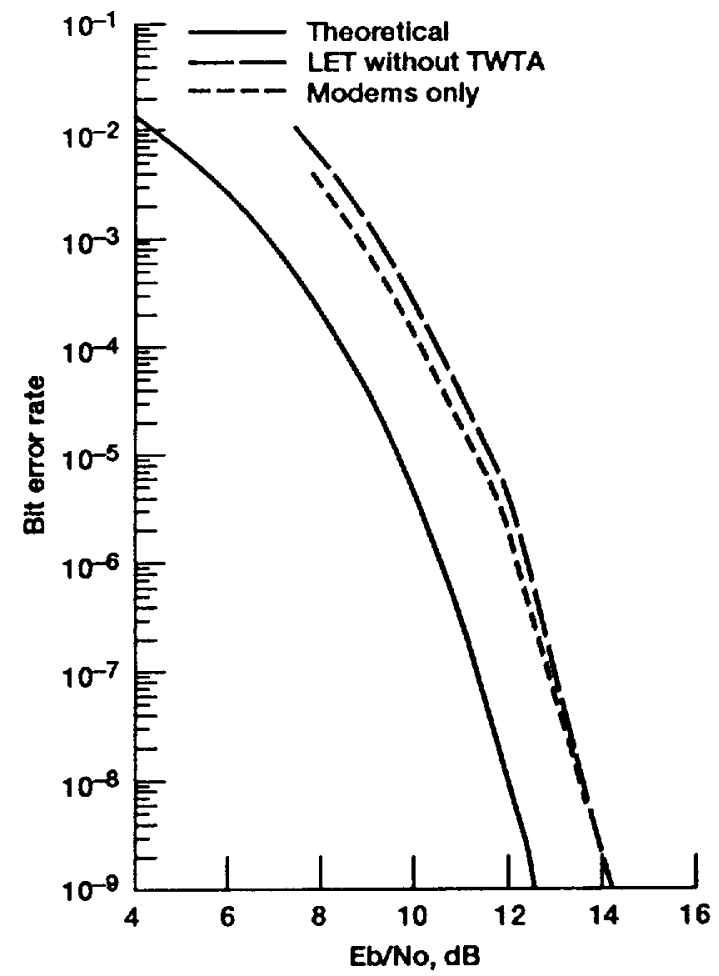

Figure 7.-BER performance of the LET Loopback path excluding the TWTA. 110.592 Mbps burst mode with 100 Mbps throughput. Modem back-to-back case included for reference.

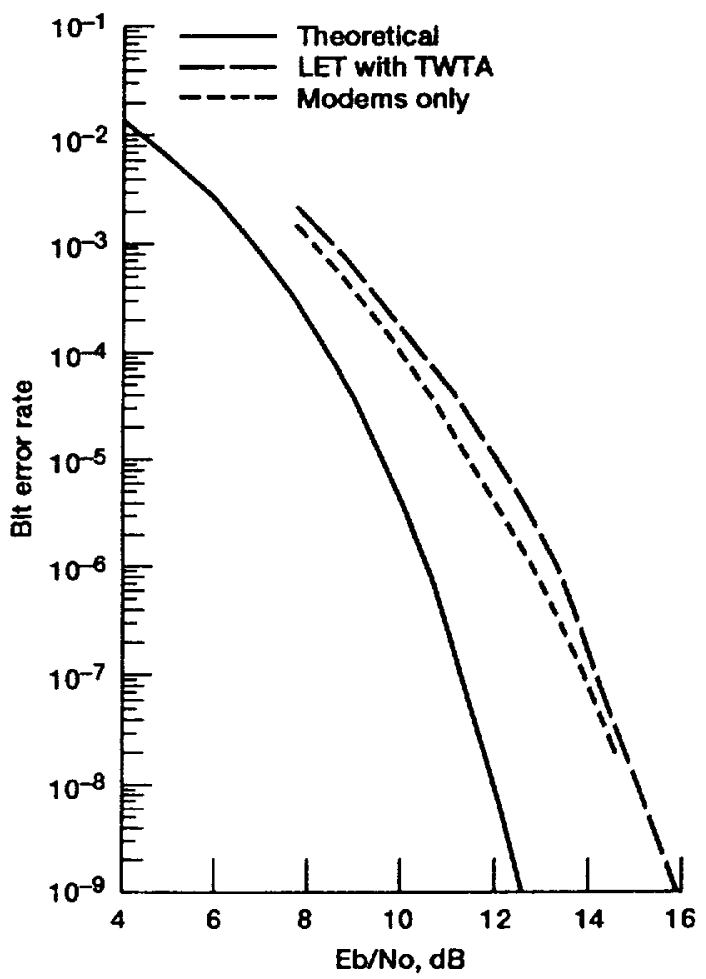

Figure 9.-BER performance of the LET Loopback path including the TWTA. 221.184 Mbps burst mode with 200 Mbps throughput. Modem back-to-back case included for reference. 

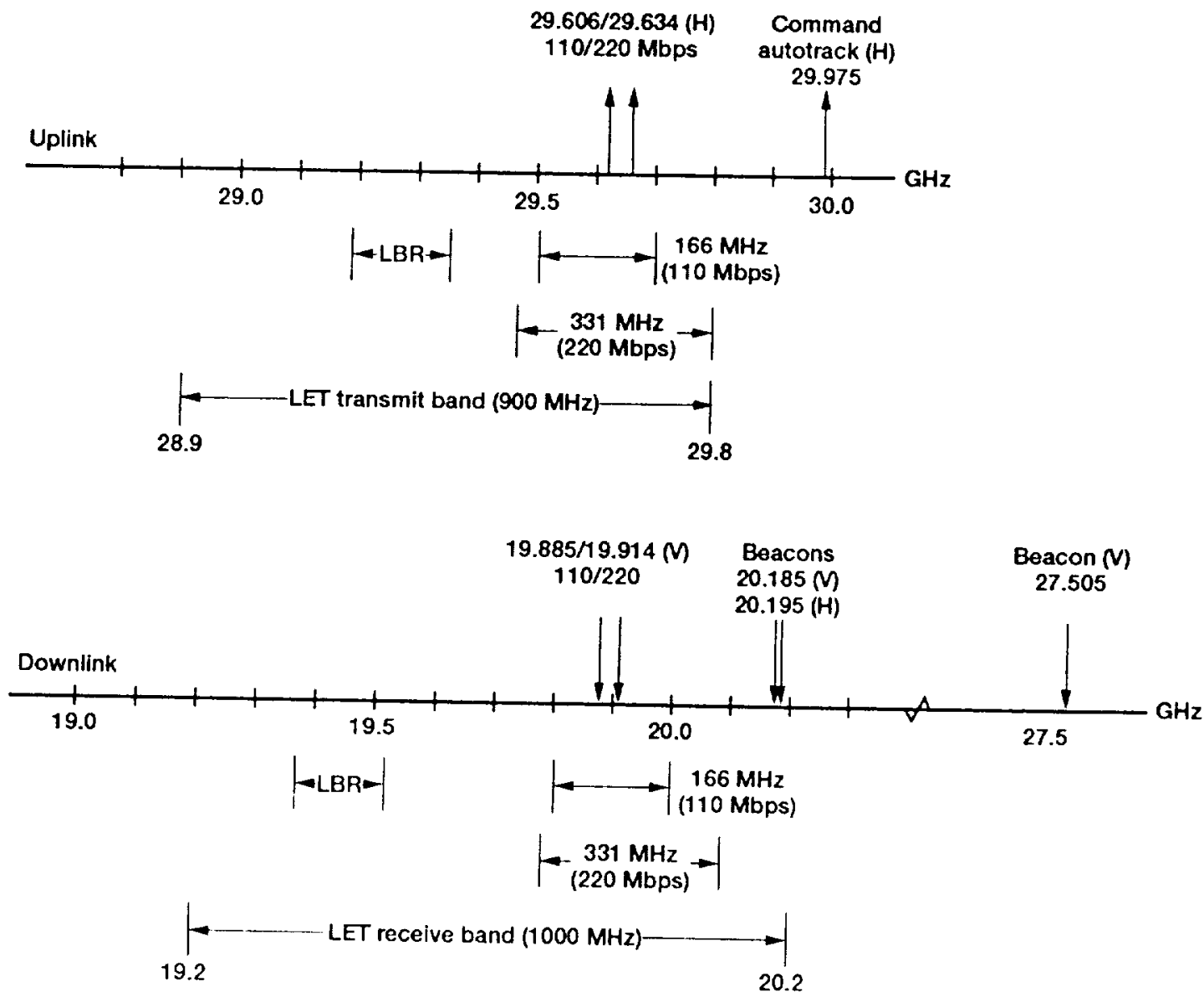

Figure 10.-LET frequency plan. 
Public reporting burden for this collection of information is estimated to average t hour per response, including the time for reviewing instructions, searching existing data sources,

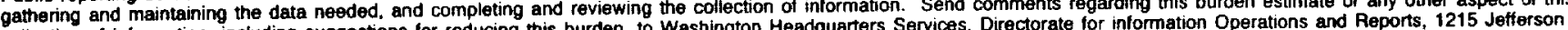
collection of information, including suggestions for reducing this burden, to Washington Headquarters Services, Directoraction Project (0704-0188), Washington, DC 20503. Davis Highway, Suite 1204, Arlington, VA 22202-4302, and to the

1. AGENCY USE ONLY (Leave blank)

\begin{tabular}{r|r|} 
2. REPORT DATE & 3. \\
1992 &
\end{tabular}

3.

\section{TITLE AND SUBTITLE}

The Link Evaluation Terminal for the Advanced Communications

Technology Satellite Experiments Program

\section{AUTHOA(S)}

Brian D. May

WU-649-40-00

echnical Memorandum

\section{PERFORMING ORGANIZATION NAME(S) AND ADDRESS(ES)}

National Aeronautics and Space Administration

Lewis Research Center

Cleveland, Ohio 44135-3191

9. SPONSORING/MONITORING AGENCY NAMES(S) AND ADDRESS(ES)

National Aeronautics and Space Administration

Washington, D.C. 20546-0001
8. PERForMing organization REPORT NUMBER

$$
\text { E- } 6735
$$

10. SPONSORING/MONITORING AGENCY REPORT NUMBER

NASA TM -105367

AIAA-92-2040

\section{SUPPLEMENTARY NOTES}

Prepared for the 14th International Communications Satellite Systems Conference sponsored by the American Institute of Aeronautics and Astronautics, Washington, D.C., March 22-26, 1992. Responsible person, Brian D. May, (216) 433-3573.

12a. DISTRIBUTION/AVAILABILITY STATEMENT

12b. DISTRIBUTION CODE

Unclassified - Unlimited

Subject Category 17

13. ABSTRACT (Maximum 200 words)

The experimental NASA satellite, Advanced Communications Technology Satellite (ACTS), introduces new technology for high throughput 30 to $20 \mathrm{GHz}$ satellite services. Contained in a single communications payload is both a regenerative TDMA system and multiple $800 \mathrm{MHz}$ "bent pipe" channels routed to spot beams by a switch matrix. While only one mode of operation is typical during any experiment, both modes can operate simultaneously with reduced capability due to sharing of the transponder. NASA Lewis Research Center instituted a ground terminal development program in anticipation of the satellite launch to verify the performance of the switch matrix mode of operations. Specific functions are built into the ground terminal to evaluate rain fade compensation with uplink power control and to monitor satellite transponder performance with bit error rate measurements. These functions were the genesis of the ground terminal's name, Link Evaluation Terminal, often referred to as LET. Connectors are included in LET that allow independent experimenters to run unique modulation or network experiments through ACTS using only the RF transmit and receive portions of LET. Capabilities that enable LET to accomplish many significant ACTS experiment goals are reviewed. Test data indicate that LET will be able to verify important parts of ACTS technology and provide independent experimenters with a useful ground terminal. Laboratory measurements of major subsystems integrated into LET are presented. Bit error rate is measured with LET in an internal loopback mode.

\section{SUBJECT TERMS}

ACTS; Extremely high frequencies; Bit error rate

\begin{tabular}{|c|c|}
\hline $\begin{array}{c}\text { 17. SECURITY CLASSIFICATION } \\
\text { OF REPORT } \\
\text { Unclassified }\end{array}$ & $\begin{array}{c}\text { 18. SECURITY CLASSIFICATION } \\
\text { OF THIS PAGE } \\
\text { Unclassified }\end{array}$ \\
\hline
\end{tabular}

19. SECURITY CLASSIFICATION OF ABSTRACT Unclassified 